\title{
Hydrodeoxygenation of bio-oil over Pt-based supported catalysts: importance of mesopores and acidity of the support to compounds with different oxygen contents $\dagger$
}

Cite this: RSC Advances, 2013, 3, 12635

Received 21st March 2013,

Accepted 19th June 2013

DOI: 10.1039/c3ra41405a

www.rsc.org/advances

\author{
Yuxin Wang, ${ }^{\text {*ab }}$ Jinhu Wu $\mathrm{W}^{\mathrm{a}}$ and Shengnian Wang ${ }^{\text {*b }}$
}

The importance of the acidity and mesoporous structure to the hydrodeoxygenation activity of catalysts for bio-oil upgrading was investigated. By testing three model bio-oil compounds, we showed that catalysts with a strong acidity (e.g. ZSM-5) have a high hydrodeoxygenation activity, while the mesoporous structure of the support can further improve the catalytic performance of ZSM-5.

\section{Introduction}

Bio-oil shows promising potential as a feedstock of hydrocarbon products to help reduce the current global challenges of fossil fuel shortage, climate change and environmental problems. ${ }^{1-3}$ However, its high corrosivity, poor thermal stability, and low heat capacity impede the wide acceptance of bio-oil in many industrial practices. ${ }^{4}$ Such poor oil quality is caused, largely, by the high oxygen content of its many compounds (up to 40\%). Currently, several approaches, including the catalytic pyrolysis of biomass, zeolite cracking, and hydrodeoxygenation, have been developed to reduce the oxygen content of bio-oil. The biomass pyrolysis process can directly convert biomass to aromatics, but with a low liquid yield. ${ }^{5}$ The catalytic cracking of bio-oil with zeolites mainly eliminates oxygen in the form of $\mathrm{CO}, \mathrm{CO}_{2}$ and $\mathrm{H}_{2} \mathrm{O}$, which results in serious coking problems. ${ }^{6}$ Compared to these two deoxygenation processes, hydrogenation, a well-developed petroleum refining technology, seems more desirable for bio-oil upgrading, because the oxygen in bio-oils can be efficiently removed as $\mathrm{H}_{2} \mathrm{O}$ during hydrogenation and most of the carbon is retained in the final hydrocarbon product, rather than resulting in coke on the catalyst. ${ }^{7}$

In the traditional hydrogenation process, sulfided Co-Mo and $\mathrm{Ni}-\mathrm{Mo}$ catalysts are commonly used to efficiently remove $\mathrm{S}, \mathrm{N}$, and

${ }^{a}$ Key Laboratory of Biofuels, Qingdao Institute of Bioenergy and Bioprocess Technology, Chinese Academy of Sciences, 189 Songling Road, Qingdao, Shandong 266101, P. R. China

${ }^{b}$ Institute for Micromanufacturing, Louisiana Tech University, 911 Hergot Avenue, Ruston, Louisiana 71270,USA.E-mail: yxwang@latech.edu; swang@latech.edu

$\dagger$ Electronic supplementary information (ESI) available. See DOI: 10.1039/c3ra41405a
O from oil. Under high temperature $(>573 \mathrm{~K})$ and high pressure $(>8 \mathrm{MPa})$ conditions, saturated hydrocarbons can be mass produced. However, such harsh hydrotreating conditions are inappropriate for bio-oil hydrodeoxygenation. ${ }^{8}$ Bio-oil would be quickly decomposed and polymerized under these conditions, resulting in a serious char-coke problem on the catalyst and a quick loss of its catalytic activity. Moreover, the low sulfur content of bio-oil compounds means it is not desired to use traditional sulfided catalysts for their hydrodeoxygenation. ${ }^{9}$ Some recent studies have found that noble metal based catalysts showed a high hydrodeoxygenation activity at lower temperatures (473 K) and no need for a pre-sulfidisation, making them suitable for bio-oil deoxygenation. ${ }^{10}$ However, further studies found that the physical and chemical properties of their support material play important roles in the catalytic activity of these catalysts. Various supports have been investigated, including alumina, silica, active carbon, and zeolites. ${ }^{11-14}$ Their various acidities and pore structures produced different catalytic activities when hydrodeoxygenating bio-oil. For example, an early study showed that Pt clusters dispersed on zeolite had a much better catalytic activity than those on alumina or silica when hydrodeoxygenating phenol-type bio-oil compounds. ${ }^{15}$ However, for large bio-oil molecules, such as phenolic oligomers and dibenzofuran (DBF), their catalytic activity was insufficient. Our early study demonstrated that when Pt was impregnated on mesoporous supports, the hydrodeoxygenation activity for DBF could be greatly improved. ${ }^{16}$ These findings suggest that both the acidity and pore structure might be important for catalysts in bio-oil hydrodeoxygenation. Hence, we prepared Pt-based catalysts with three different support materials and explored the importance of the acidity and mesopores on the catalytic performance. Specifically, Pt supported on the conventional $\mathrm{Al}_{2} \mathrm{O}_{3}$ (mesoporous support with weak acidity), zeolite ZSM5 (microporous support with strong acidity), and mesoporous zeolite $\mathrm{ZSM}-5^{17}$ (MZSM-5 with hierarchical porosity and strong acidity), were used in the evaluation. Three common bio-oil compounds with various oxygen contents and molecular sizes, dibenzofuran (DBF, $\mathrm{C}_{12} \mathrm{H}_{8} \mathrm{O}$ with a 9 wt.\% oxygen content, $0.87 \times$ $0.50 \mathrm{~nm}$ molecule size), cresol $\left(\mathrm{C}_{7} \mathrm{H}_{8} \mathrm{O}\right.$ with 15 wt.\% oxygen content, $0.59 \times 0.50 \mathrm{~nm}$ molecule size), and guaiacol (GUA, 
$\mathrm{C}_{7} \mathrm{H}_{8} \mathrm{O}_{2}$ with 25 wt.\% oxygen content and $0.72 \times 0.50 \mathrm{~nm}$ molecule size), were used as model bio-oil compounds to evaluate the bio-oil hydrodeoxygenation on these three catalysts.

\section{Experimental}

\subsection{Catalyst preparation}

2.1.1. $\mathrm{Pt}-\mathrm{Al}_{2} \mathrm{O}_{3}$ hydrodeoxygenation catalyst preparation. The $\mathrm{Pt}-\mathrm{Al}_{2} \mathrm{O}_{3}$ catalyst was prepared by a conventional incipient wetness impregnation method. The $\mathrm{Al}_{2} \mathrm{O}_{3}$ (Shandong Alumina Corporation, China) was added to $\mathrm{a}_{2} \mathrm{PtCl}_{6} \cdot 6 \mathrm{H}_{2} \mathrm{O}(99 \%$; Aladdin Industrial Inc.) aqueous solution, heated to $673 \mathrm{~K}$, and held for $4 \mathrm{~h}$ in air before impregnation. The catalyst precursor was then evaporated at ambient temperature for another $12 \mathrm{~h}$, and then dried in an oven at $373 \mathrm{~K}$ for $12 \mathrm{~h}$. Finally the catalyst was calcined at $773 \mathrm{~K}$ for $4 \mathrm{~h}$ (with a heating rate of $1 \mathrm{~K} \mathrm{~min}^{-1}$ ). The Pt loading in the sample was 0.5 wt.\%.

2.1.2. Zeolite and zeolite supported Pt hydrodeoxygenation catalyst preparation. For the mesoporous zeolite MZSM-5 synthesis, tetraethylorthosilicate (TEOS, 99\%; Aladdin Industrial Inc.), aluminum isopropoxide (99\%; Aladdin Industrial Inc.), and tetrapropylammonium hydroxide (TPAOH, 25 wt.\% in water; Aladdin Industrial Inc.) were firstly added under vigorous stirring with a pre-calculated ratio of 3[(trimethoxysilyl)propyl]octyldimethyl-ammonium chloride (TPOAC, $42 \%$ in methanol; AEGIS Company) and cetyl trimethylammonium bromide (CTAB, >99\%; Aladdin Industrial Inc.) until a clear solution was obtained. The final molar composition of the synthesized solution was $\mathrm{SiO}_{2}: \mathrm{Al}_{2} \mathrm{O}_{3}$ : TPAOH: TPOAC: CTAB: $\mathrm{H}_{2} \mathrm{O}=30: 1.0$ 6.0: $0.6: 0.6: 2400$. The mixture was further stirred for $2 \mathrm{~h}$ at room temperature and then transferred to a Teflon lined autoclave and kept at $423 \mathrm{~K}$ for $48 \mathrm{~h}$. After crystallization, the solid product was separated by filtration, washed several times with DI water, and then dried at $373 \mathrm{~K}$ for $12 \mathrm{~h}$ in ambient air. After further calcination in air at $823 \mathrm{~K}$ for $5 \mathrm{~h}$, the $\mathrm{H}$-form of the sample was ion-exchanged three times with a $0.1 \mathrm{M} \mathrm{NH}_{4} \mathrm{NO}_{3}$ solution at $363 \mathrm{~K}$ for $90 \mathrm{~min}$ (liquid/ solid ratio of $10 \mathrm{~cm}^{3} \mathrm{~g}^{-1}$ ) with gentle agitation. The sample was then filtered, washed extensively with DI water, and dried at 373 $\mathrm{K}$ for $4 \mathrm{~h}$. The dried zeolite sample was finally calcined in a quartz furnace by raising the furnace temperature from ambient to $773 \mathrm{~K}$ with a $1 \mathrm{~K} \mathrm{~min}^{-1}$ ramp rate and held there for another $6 \mathrm{~h}$. The conventional microporous zeolite ZSM-5 was also synthesized through a similar hydrothermal process aforementioned, but without adding the TPOAC and CTAB.

Pt was dispersed on $\mathrm{Al}_{2} \mathrm{O}_{3}, \mathrm{ZSM}-5$, and MZSM-5 through an incipient wetness impregnation method. The Pt loading in all three catalysts was 0.5 wt. $\%$.

\subsection{Catalyst characterization}

X-ray diffraction (XRD) analysis was done on a Bruker D8 Advance $\mathrm{X}$-ray diffractometer, using $\mathrm{Cu}-\mathrm{K} \alpha$ radiation at room temperature with instrumental settings of $40 \mathrm{kV}$ and $40 \mathrm{~mA}$. Data were recorded in the $2 \theta$ range $5-50^{\circ}$ with a $0.02^{\circ}$ step size.

Scanning electron microscopy (SEM) images were taken on a Hitachi S-4800 instrument. Samples were prepared by dusting the zeolite powder onto double sided carbon tape, mounted on an alumina stub. All samples were subsequently sputter coated with a thin gold film to reduce charging effects.

Nitrogen adsorption isotherms were obtained at $77 \mathrm{~K}$ on a Micromeritics ASAP 2020 Surface Area and Porosity Analyzer in the relative pressure range from 0.05 to 0.99 . Before measurement, samples were degassed at $573 \mathrm{~K}$ for $6 \mathrm{~h}$. The total surface area of the catalyst was calculated according to the Brunauer-EmmettTeller (BET) method (note: the BET method may underestimate the specific area of a microporous zeolite $\left.{ }^{18}\right)$. The mesopore distribution was obtained by the Barrett-Joyner-Halenda $(\mathrm{BJH})$ analysis of the adsorption branch of the isothermal curve.

Hydrogen chemisorption was done on a Micromeritics ASAP 2020C instrument to determine the Pt dispersion on the support. This was done by calculating the difference between the two adsorption isotherms (strong $\mathrm{H}_{2}$ adsorption) and extrapolating the curves to zero pressure, assuming $\mathrm{H} / \mathrm{M}=1$ at the metal surface.

The acidity of the zeolites and alumina was evaluated by the classic reaction of 2-methyl-2-pentene (2M2P) isomerization, according to ref. 19. The conversion and molar ratio of trans-3methyl-2-pentene (trans-3M2P) to trans- and cis-4-methyl-2-pentene (trans- and cis-4M2P) were used to quantify the acidity (a high conversion and high molar ratio indicates a stronger acidity). The isomerization of $2 \mathrm{M} 2 \mathrm{P}$ was undertaken in a quartz tube reactor and a mixture of $7 \% 2 \mathrm{M} 2 \mathrm{P}$ in helium vapor moved over $0.1 \mathrm{~g}$ of the catalyst at $423 \mathrm{~K}$ for $10 \mathrm{~min}$. The products were analyzed online on an Agilent 7890 GC with an FID detector using a $50 \mathrm{~m}$ HP5 packed column. Before the isomerization experiments, the catalysts were pretreated in a helium flow for about $1 \mathrm{~h}$ at $723 \mathrm{~K}$.

\subsection{Catalytic experiments}

The hydrodeoxygenation experiments were performed at $473 \mathrm{~K}$ and $4 \mathrm{MPa}$ in a fixed-bed reactor $(10 \mathrm{~mm}$ in diameter and $420 \mathrm{~mm}$ in length). The catalyst ( $1.5 \mathrm{~g}$ ) with a particle size of $250-420 \mu \mathrm{m}$ was loaded into the reactor. Prior to the hydrodeoxygenation, the catalyst was reduced under $\mathrm{a}_{2}$ atmosphere at $733 \mathrm{~K}$ for $3 \mathrm{~h}$, and then cooled down to the reaction temperature. The model compound, GUA, cresol, or DBF, was dissolved in $n$-tridecane with a 3 wt.\% content and then fed into the reactor. The hydrodeoxygenation evaluation was done at four different liquid hourly space velocities (LHSVs): $1,2,4$, and $6 \mathrm{~h}^{-1}$ with the $\mathrm{H}_{2}$ /oil (oxygenated compounds plus $n$-tridecane) volume ratio fixed at 600. After the reaction reached steady-state, the products were analyzed off-line with an Agilent GC-MS 7890A-5975C using a $30 \mathrm{~m}$ HP-INNOWax column. The conversion of the model compounds was determined by the amount of reactant recovered after the reaction and the hydrodeoxygenation degree was determined by the amount percent of all the non-oxygen products.

\section{Results and discussion}

The XRD patterns of the mesoporous ZSM-5 (MZSM-5) and the common ZSM-5 samples (Fig. 1a) show well-resolved peaks which belong to the mordenite framework inverted (MFI) zeolite structure. The high adsorbed amount at low $P / P_{0}$ and the hysteresis loop at high $P / P_{0}(>0.4)$ are clearly shown in the nitrogen adsorption-desorption isotherms of the MZSM-5 sample (Fig. 1b). This indicated that our MZSM-5 samples were zeolites 
(a)

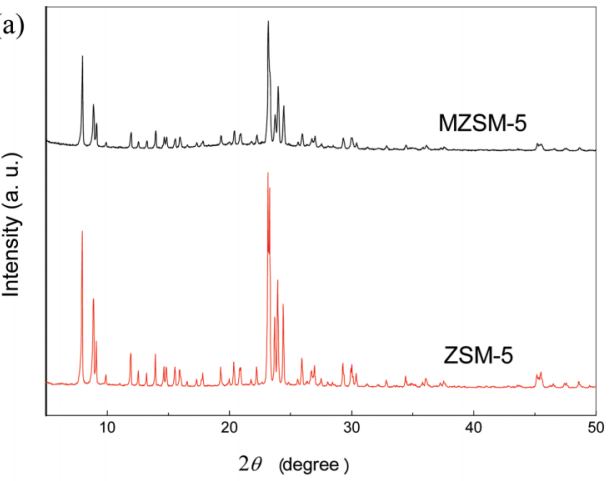

(c)

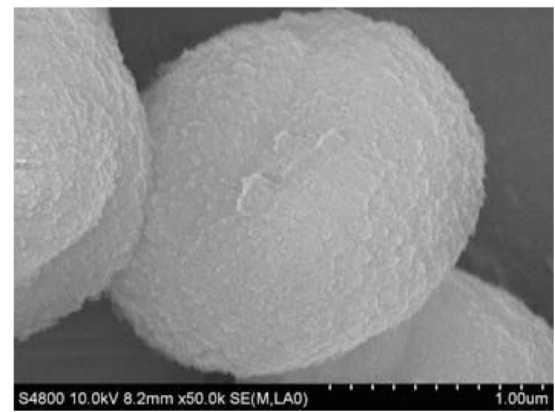

(b)

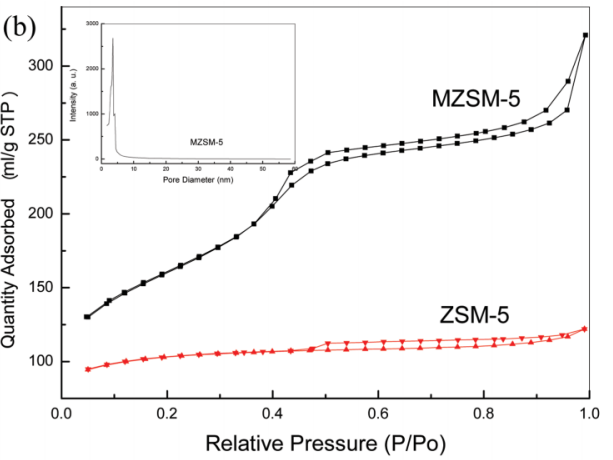

(d)

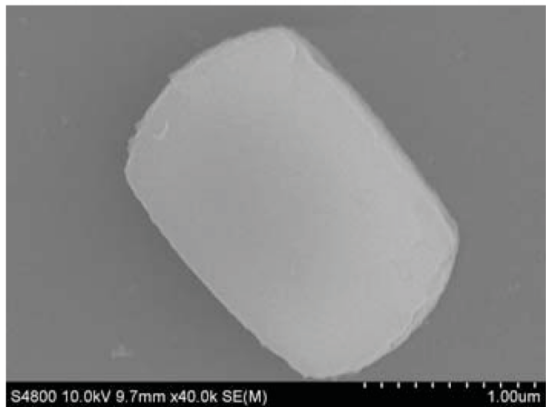

Fig. 1 Physical and chemical characteristics of MZSM-5 and ZSM-5: (a) XRD, (b) nitrogen adsorption-desorption isotherms, SEM images of (c) MZSM-5 and (d) ZSM-5.

with both micropores and mesopores. Moreover, a very narrow pore distribution centred at $3.6 \mathrm{~nm}$ was also observed for the MZSM-5 sample (see the inset of Fig. 1b). In contrast, the conventional ZSM-5 sample showed only a type I isotherm, which is typical for microporous materials. The detailed sorption data shown in Table 1 indicated that the MZSM-5 sample had a much higher BET special surface area and pore volume than those of the ZSM-5 sample. From the SEM images, the MZSM-5 sample (Fig. 1c) exhibited a "rounded boat" shape, a typical morphology of MFI structured crystals, which was different to the tablet morphology of the ZSM-5 sample (Fig. 1d). In order to compare the acidity of these samples, the model reaction of $2 \mathrm{M} 2 \mathrm{P}$ isomerization over the catalysts was done. As shown in Table 1, the MZSM-5 and ZSM-5 samples showed a similar 2M2P conversion and molar ratio of trans-3M2P to trans- and cis-4M2P, which were much higher than those on the $\mathrm{Al}_{2} \mathrm{O}_{3}$ sample. In fact, no trans-3M2P was detected in the products of the $\mathrm{Al}_{2} \mathrm{O}_{3}$ sample. This confirmed the comparable strong acidity of the MZSM-5 and ZSM-5 and the weak acidity of the $\mathrm{Al}_{2} \mathrm{O}_{3}$. The textural parameters and the acidity data summarized in Table 1 clearly show the presence of a mesoporous structure in the $\mathrm{Al}_{2} \mathrm{O}_{3}$ and MZSM-5 samples while only a microporous structure for the ZSM-5. The hydrogen chemisorption results showed that the Pt dispersion on MZSM-5 and ZSM-5 is similar (33\% for MZSM-5 and 32\% for ZSM5) while much higher on $\mathrm{Pt}-\mathrm{Al}_{2} \mathrm{O}_{3}$ (76\%). The low Pt dispersion over MZSM-5 and ZSM-5 is believed to be the result of strong interactions between the zeolites and the $\mathrm{PtCl}_{6}{ }^{2-}$ precursor.

Fig. 2-4 show the hydrodeoxygenation performance of three bio-oil model compounds, DBF, cresol, and GUA, respectively. Fig. 2 shows the hydrodeoxygenation performance of DBF, a biooil component with only 9 wt.\% oxygen content, over the three catalysts (Pt-ZSM-5, Pt-MZSM-5, and $\mathrm{Pt}-\mathrm{Al}_{2} \mathrm{O}_{3}$ ). All three catalysts were quite efficient for DBF conversion and hydrodeoxygenation, which is consistent with our earlier study. ${ }^{20}$ The low oxygen content led to the easy deoxygenation of DBF on the Pt-based catalysts, so that the contribution from all three support materials was only marginal unless very high LHSVs (e.g., 4-6 $\mathrm{h}^{-1}$ ) were used. At high LHSVs, the Pt-MZSM-5 showed the best DBF conversion and hydrodeoxygenation degree among the three catalysts, with a nearly complete deoxygenation of DBF even at $\mathrm{LHSV}=6 \mathrm{~h}^{-1}$. $\mathrm{Pt}-\mathrm{Al}_{2} \mathrm{O}_{3}$ also showed a very good hydrodeoxygenation performance with the DBF conversion reaching $\sim 98 \%$ at the

Table 1 The pore structure, acidity characteristics and Pt dispersion of the supports

\begin{tabular}{|c|c|c|c|c|c|c|c|}
\hline Support & $\begin{array}{l}\text { BET surface } \\
\text { area }\left(\mathrm{m}^{2} \mathrm{~g}^{-1}\right)\end{array}$ & $\begin{array}{l}\text { Pore volume } \\
\left(\mathrm{cm}^{3} \mathrm{~g}^{-1}\right)\end{array}$ & $\begin{array}{l}D_{\text {meso }}{ }^{a} \\
(\mathrm{~nm})\end{array}$ & $\begin{array}{l}\text { 2M2P conversion } \\
(\%)^{b}\end{array}$ & $\begin{array}{l}\text { Molar } \\
\text { ratio }^{c}\end{array}$ & $\begin{array}{l}\text { Pt loading } \\
\text { (wt.\%) }\end{array}$ & $\begin{array}{l}\text { Pt dispersion } \\
(\%)\end{array}$ \\
\hline $\mathrm{Al}_{2} \mathrm{O}_{3}$ & 240 & 0.39 & 4.9 & 21 & 0 & 0.5 & 76 \\
\hline ZSM-5 & 319 & 0.10 & N. A. & 55 & 1.7 & 0.5 & 32 \\
\hline MZSM-5 & 506 & 0.51 & 3.6 & 60 & 1.5 & 0.5 & 33 \\
\hline
\end{tabular}

${ }^{a}$ Mesopore diameter. ${ }^{b}$ Conversion of $2 \mathrm{M} 2 \mathrm{P}$ at $423 \mathrm{~K} .{ }^{c}$ Molar ratio of trans-3M2P to trans- and cis-4M2P. 
(a)

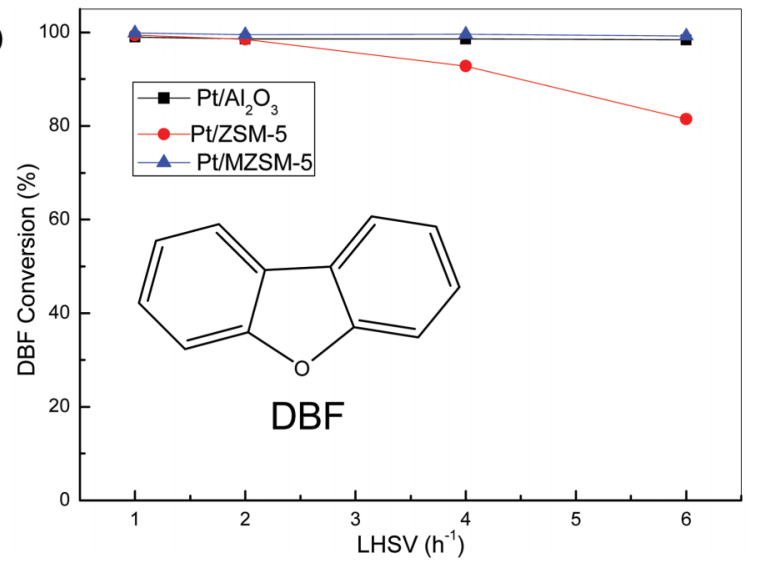

(b)

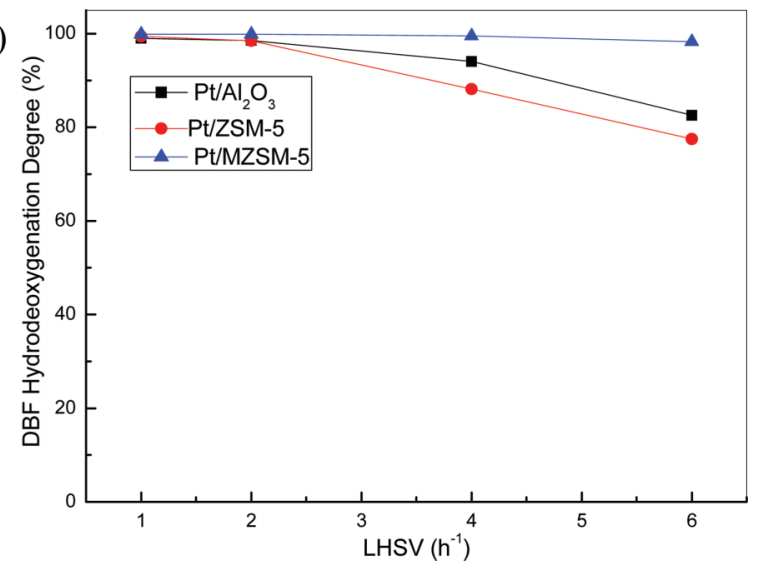

Fig. 2 The DBF conversion (a) and deoxygenation degree (b) over three Pt-based catalysts.

LHSV of $6 \mathrm{~h}^{-1}$. Both were much higher than that of the Pt-ZSM-5 with $\sim 81 \%$ DBF conversion. This suggests that for large size hydrocarbons with a low oxygen content, such as DBF (note: DBF has the largest molecular size of the three model compounds), a mesoporous structure is essential to attain a high catalytic conversion. A number of intermediate products were detected during the DBF hydrodeoxygenation. At low LHSVs, the major products include deoxygenated and saturated hydrocarbons such as bicyclohexyl and (cyclopentylmethyl)cyclohexane. With an increase in LHSV, the Pt-MZSM-5 still retained a high hydrodeoxygenation ability and almost no oxygenated hydrocarbons in its products. However, for the Pt-ZSM-5 and $\mathrm{Pt}-\mathrm{Al}_{2} \mathrm{O}_{3}$, some oxygenated hydrocarbons were clearly detected, although the oxygen containing compounds were different. For Pt-ZSM-5, the un-reacted DBF was the main oxygen containing compound in the products, while aromatic alcohols or saturated aromatic alcohols dominated the oxygenated hydrocarbons in the products of Pt$\mathrm{Al}_{2} \mathrm{O}_{3}$. This suggests that the strong acidity helps further improve the deoxygenation.

For high oxygen content compounds such as cresol, the difference in the hydrodeoxygenation performance of the three catalysts was more obvious (Fig. 3). Compared to that of DBF, the conversion of cresol over all three catalysts was lower. Pt-MZSM-5 still exhibited a very high activity with the cresol conversion of $\sim 98 \%$ at LHSV $=1 \mathrm{~h}^{-1}$. The difference between the two mesoporous catalysts, Pt-MZSM-5 and $\mathrm{Pt}-\mathrm{Al}_{2} \mathrm{O}_{3}$, was very obvious $\left(\sim 85 \%\right.$ for $\mathrm{Pt}-\mathrm{Al}_{2} \mathrm{O}_{3}$ at LHSV $\left.=1 \mathrm{~h}^{-1}\right)$ while the performance of PtZSM-5 $\left(\sim 93 \%\right.$ at LHSV $\left.=1 \mathrm{~h}^{-1}\right)$ was in between the other two catalysts. With an increase in the LHSV, the conversion of cresol was only slightly reduced over Pt-MZSM-5 (change from 98\% to 93\% when the LHSV increased from $1 \mathrm{~h}^{-1}$ to $6 \mathrm{~h}^{-1}$ ). A similar reduction in the conversion also occurred on the Pt-ZSM-5 catalyst (from 93\% to 80\%). The cresol conversion over $\mathrm{Pt}-\mathrm{Al}_{2} \mathrm{O}_{3}$ was affected sharply by the LHSV (change from $85 \%$ to $24 \%$ when the LHSV increased from $1 \mathrm{~h}^{-1}$ to $6 \mathrm{~h}^{-1}$ ). These facts suggest that the acidity of the support material becomes dominant in the cresol conversion. Moreover, $\mathrm{Pt}-\mathrm{Al}_{2} \mathrm{O}_{3}$ also showed a much poorer hydrodeoxygenation performance than Pt-MZSM-5 or Pt-ZSM-5. Over Pt-MZSM-5 and Pt-ZSM-5, the main products were methylcyclohexane and other alkylated cycloalkanes, while over $\mathrm{Pt}-\mathrm{Al}_{2} \mathrm{O}_{3}$, the main product was the oxygenated hydrocarbon, methylcyclohexanol. This further confirms that a catalyst with a strong acidity has a better hydrodeoxygenation ability than a weak acidity catalyst, which is particularly true for compounds with a high oxygen content. The mesoporous structure allows a deep diffusion and adsorption of cresol, to reach more Pt active sites to

(a)

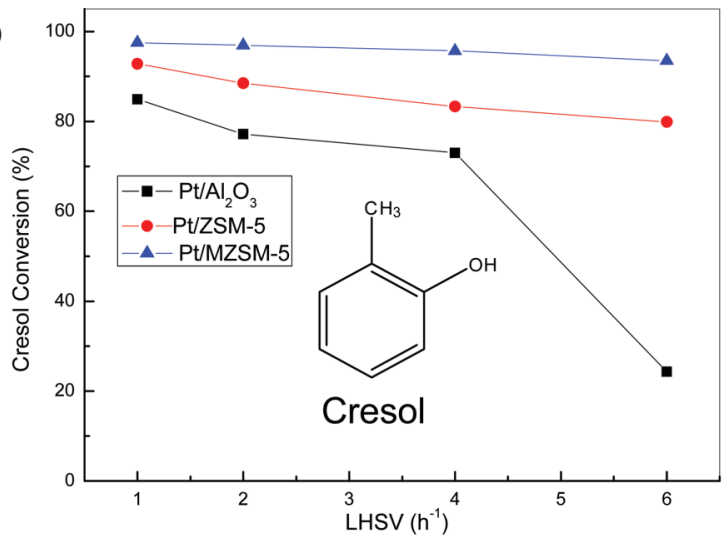

(b)

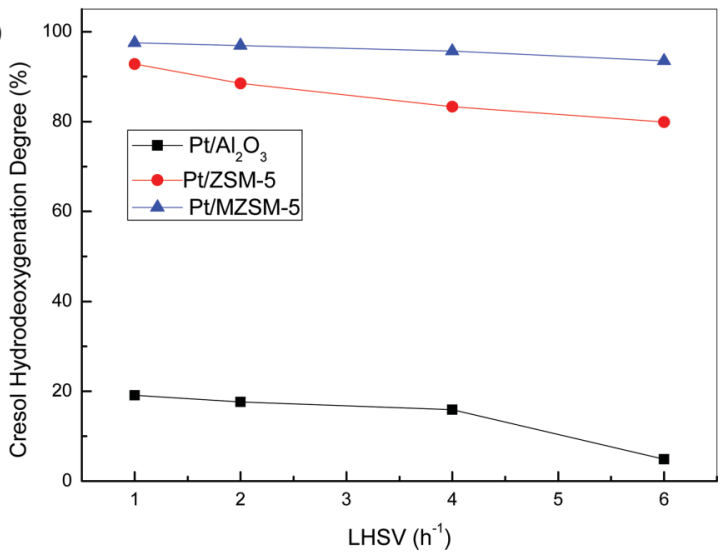

Fig. 3 The cresol conversion (a) and deoxygenation degree (b) over three Pt-based catalysts. 


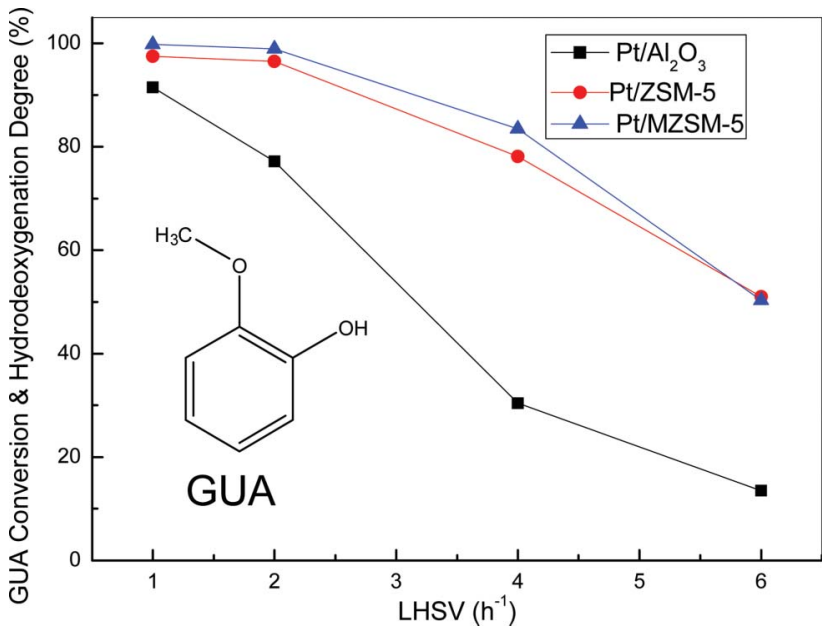

Fig. 4 The GUA conversion and deoxygenation degree over three Pt-based catalysts.

further increase the catalytic conversion. Therefore, the mesoporous ZSM-5 (MZSM-5) could further improve the hydrodeoxygenation of cresol with more oxygenated hydrocarbons than the conventional ZSM-5.

When further increasing the oxygen content, hydrodeoxygenation became difficult for all three Pt-based catalysts. Fig. 4 shows the conversion and hydrodeoxygenation activity of all three catalysts for GUA. As no oxygen containing compounds were detected in the products, the GUA conversion and hydrodeoxygenation degree have essentially the same value at all the experimental LHSVs. As shown in Fig. 4, the catalysts with a strong acidity (Pt-MZSM-5 and Pt-ZSM-5) exhibited a better hydrodeoxygenation ability than the weak acidity catalyst $\left(\mathrm{Pt}-\mathrm{Al}_{2} \mathrm{O}_{3}\right)$. The GUA conversion reached $\sim 98 \%$ for Pt-MZSM-5 and Pt-ZSM-5 and $91 \%$ for $\mathrm{Pt}_{-} \mathrm{Al}_{2} \mathrm{O}_{3}$ at $\mathrm{LHSV}=1 \mathrm{~h}^{-1}$. The conversion of GUA decreased as LHSV increased for all three catalysts, and was affected most over Pt- $\mathrm{Al}_{2} \mathrm{O}_{3}$. For Pt-MZSM-5 and Pt-ZSM-5, a very similar GUA conversion (and hydrodeoxygenation degree) was found, which decreased gradually with an increase in the LHSV and reached $\sim 50 \%$ at LHSV $=6 \mathrm{~h}^{-1}$. At the same LHSV, only $\sim 13 \%$ of GUA was hydrodeoxygenated over the $\mathrm{Pt}-\mathrm{Al}_{2} \mathrm{O}_{3}$. This confirms again that the acidity of the catalyst dominates the hydrodeoxygenation of compounds with a high oxygen content, so that the contribution from the different pore structures of PtMZSM-5 and Pt-ZSM-5 is almost negligible. As the molecular size of GUA is slightly smaller than that of DBF, the low hydrodeoxygenation activity of GUA may be attributed to several facts or their combinations: (i) the oxygen content of GUA is too high to produce sufficient completely oxygenated hydrocarbons over MZSM-5 with its mesoporous size $(\sim 3.6 \mathrm{~nm})$ and (ii) very serious coke problems on the Pt active sites of the catalyst. To tackle these problems, ZSM-5 with larger mesopores, other zeolites with a stronger acidity or their combination, would be desirable.

Based on the aforementioned results, supports with a strong acidity and relatively large pores are important for the catalytic hydrodeoxygenation of bio-oil. Pt-based catalysts are well known for their strong capability in hydrogen dissociation, even if partially poisoned. ${ }^{21,22}$ The acidic sites on the support material help retain such advantages, making Pt catalysts more resistant to poisoning when they are electron-deficient. ${ }^{23}$ Therefore, Pt-based catalysts over strong acidic supports are always favorable for hydrodeoxygenation, particularly for compounds with a high oxygen content. The large pore size of the support materials allows the deep diffusion of aromatic molecules and their absorption around exposed Pt active sites, so that hydrogen spilt-over on $\mathrm{Pt}$ clusters can be immediately utilized during the hydrogenation. ${ }^{24}$ This explains why Pt-MZSM-5 has the best hydrodeoxygenation performance for all three model bio-oil compounds. With an increase in the oxygen content, the catalyst acidity becomes the dominant factor, particularly for compounds which easily lead to polymerization and coke from oxygen hydrocarbons. With a similar acidity, supports with large pores (i.e., mesoporous supports) exhibited a further improvement in the hydrodeoxygenation performance, due to their higher catalytic conversion. Such findings provide important guidelines for bio-oil hydrodeoxygenation. The mesoporous zeolites with hierarchical porosity and strong acidity are generally preferred for Pt-based catalysts in biooil hydrodeoxygenation. However, because of the complicated composition of bio-oil, mesoporous zeolites with an appropriate combination of mesopores and acidity seem necessary. Considering the broad variety of bio-oil compounds from different synthetic routes (i.e., with different size and oxygen content), further investigation is needed to find out how the pore size and acidity of mesoporous zeolites affect the conversion and hydrodeoxygenation of major bio-oil compounds, particularly those challenging ones, like GUA.

\section{Conclusions}

We investigated the importance of the acidity and mesoporous structure of Pt-based catalysts to the hydrodeoxygenation of three model compounds of bio-oil. It was found that the strong acidity of the support material was essential for the hydrodeoxygenation of high oxygen content compounds. Relatively large pores on mesoporous zeolites could help overcome the diffusion and adsorption limitations on Pt active sites to further enhance the catalytic activity. For tougher compounds with an extremely high oxygen content, supports with stronger acidity, larger pores, or their combination seem necessary. Further precise tuning of the acidity and pore size is required to achieve a more effective hydrodeoxygenation performance for major bio-oil compounds.

\section{Acknowledgements}

This work was supported by the National Basic Research Program of China (973 Program) No.2011CB201502 and Louisiana Tech University, College of Engineering and Science (Harrelson Family Professorship).

\section{Notes and references}

1 Y. C. Sharma, B. Singh and J. Korstad, Green Chem., 2011, 13, 2993. 
2 G. W. Huber, S. Iborra and A. Corma, Chem. Rev., 2006, 106, 4044.

3 P. Wang, Y. Duan, D. Link and B. Morreale, RSC Adv., 2012, 2, 9727.

4 T. P. Vispute and G. W. Huber, Green Chem., 2009, 11, 1433.

5 T. R. Carlson, T. P. Vispute and G. W. Huber, ChemSusChem, 2008, 1, 397.

6 E. Taarning, C. M. Osmundsen, X. Yang, B. Voss, S. I. Andersen and C. H. Christensen, Energy Environ. Sci., 2011, 4, 793.

7 S. Zhang, Y. Yan, Z. Ren and T. Li, Energ. Source., 2003, 25, 57.

8 M. A. Domínguez-Crespo, A. M. Torres-Huerta, L. Díaz-García, E. M. Arce-Estrada and E. Ramírez-Meneses, Fuel Process. Technol., 2008, 89, 788.

9 Q. Bu, H. Lei, A. H. Zacher, L. Wang, S. Ren, J. Liang, Y. Wei, Y. Liu, J. Tang, Q. Zhang and R. Ruan, Bioresour. Technol., 2012, 124, 470.

10 C. S. Song and A. Schmitz, Energy Fuels, 1997, 11, 656.

11 A. Niquille-Röthlisberger and R. Prins, J. Catal., 2006, 242, 207.

12 C. V. Loricera, P. Castaño, A. Infantes-Molina, I. Hita, A. Gutiérrez, J. M. Arandes, J. L. G. Fierro and B. Pawelec, Green Chem., 2012, 14, 2759.
13 J. Wildschut, M. Iqbal, F. H. Mahfud, I. Melián Cabrera, R. H. Venderbosch and H. J. Heeres, Energy Environ. Sci., 2010, 3, 962.

14 P. T. M. Do, A. J. Foster, J. Chen and R. F. Lobo, Green Chem., 2012, 14, 1388.

15 D. Y. Hong, S. J. Miller, P. K. Agrawal and C. W. Jones, Chem. Commun., 2010, 46, 1038.

16 Y. Wang, Y. Fang, T. He, H. Hu and J. Wu, Catal. Commun., 2011, 12, 1201.

17 Y. Sun and R. Prins, Angew. Chem., Int. Ed., 2008, 47, 8478.

18 X. Du and E. Wu, J. Phys. Chem. Solids, 2007, 68, 1692.

19 G. M. Kramer and G. B. McVicker, Acc. Chem. Res., 1986, 19, 78.

20 Y. Wang, T. He, K. Liu, J. Wu and Y. Fang, Bioresour. Technol., 2012, 108, 280.

21 L. Simon, J. G. van Ommen, A. Jentys and J. A. Lercher, J. Phys. Chem. B, 2000, 104, 11644.

22 L. J. Simon, J. G. van Ommen, A. Jentys and J. A. Lercher, J. Catal., 2001, 201, 60.

23 W. M. H. Sachtler and A. Yu. Stakheev, Catal. Today, 1992, 12, 283.

24 T. Tang, C. Yin and L. Wang, J. Catal., 2007, 249, 111. 